Review Article

\title{
Endoscopic scores for inflammatory bowel disease in the era of 'mucosal healing': Old problem, new perspectives
}

\author{
Cristiano Pagnini ${ }^{a}, *$, Francesca Menasci ${ }^{a}$, Federico Desideri ${ }^{a}$, Vito D. Corleto ${ }^{b}$, \\ Gianfranco Delle Fave ${ }^{a}$, Emilio Di Giulio ${ }^{\mathrm{b}}$ \\ a "Sapienza" University of Rome, Faculty of Medicine and Psychology, Digestive and Liver Disease Unit, S. Andrea Hospital, Rome, Italy \\ ${ }^{\mathrm{b}}$ Digestive Endoscopy Unit, S. Andrea Hospital, Rome, Italy
}

\section{A R T I C L E I N F O}

\section{Article history:}

Received 28 January 2016

Accepted 7 March 2016

Available online 14 March 2016

\section{Keywords:}

Crohn's disease

Endoscopic score

Inflammatory bowel disease

Mucosal healing

Ulcerative colitis

\begin{abstract}
A B S T R A C T
The importance of the endoscopic evaluation in inflammatory bowel disease (IBD) management has been recognized for many years. However, the modalities for reporting endoscopic activity represent an ongoing challenge. To address this, several endoscopic scores have been proposed. Very few have been properly validated, and the use of such tools remains sub-optimal and is mainly restricted to clinical trials. In recent years, a growing emphasis of the concept of 'mucosal healing' as a prognostic marker and therapeutic goal has increased the need for a more accurate definition of endoscopic activity in both ulcerative colitis (UC) and Crohn's Disease (CD). In the present review, the evolution of the challenges related to endoscopic scores in IBD has been analyzed, with particular attention paid to the renewed relevance of endoscopic activity in recent years. Currently, despite the growing relevance of endoscopic activity, evaluating this activity in IBD is still a challenge. The implementation of efficacious endoscopic scores and a better definition of the absence of activity (mucosal healing) are needed.
\end{abstract}

(C) 2016 Editrice Gastroenterologica Italiana S.r.l. Published by Elsevier Ltd. All rights reserved.

\section{Introduction}

Inflammatory bowel disease (IBD) is a pathologic condition that causes chronic inflammation and may involve several tracts of the intestine. The relevance of the endoscopic evaluation in the management of IBD for diagnosis and follow-up is indisputable. This is particularly true for ulcerative colitis (UC), which is characterized by a mucosal inflammation that does not cross the lamina propria and that involves only the colon to varying degrees [1]. By contrast, in Crohn's Disease (CD) the inflammation is typically transmural and may involve several intestinal tracts, including areas not easily accessible by an endoscope [2].

Several scores for the evaluation of endoscopic activity in IBD have been proposed. Although the first attempts to establish a numeric score to evaluate the endoscopic activity of UC date back to the 1950s, the challenge of correctly interpreting and codifying endoscopic features has not been solved, and the issue has become more important over the last decade. The wider utilization of potent therapeutic options for IBD patients, such as biologic drugs, has led to a consistent conceptual modification of the clinical

\footnotetext{
* Corresponding author at: “Sapienza” University of Rome, S. Andrea Hospital, Via di Grottarossa 1035, 00189 Rome, Italy. Tel.: +39 0633779; fax: +39 0633776601. E-mail address: cristiano.pagnini@uniroma1.it (C. Pagnini).
}

management, with a subsequent need for the identification of new end-points for the evaluation of therapeutic efficacy. This process has helped move endoscopic activity evaluation toward the more stringent concept of 'mucosal healing' (MH). In fact, a growing body of evidence suggests that the complete resolution of evident signs of inflammation during an endoscopic examination is associated with a better long-term outcome in terms of shorter hospital stays, an increase in sustained remission, and a decrease in the need for surgery [3]. The evidence for and limitations of the MH concept are still matter of debate in the literature [4] and are beyond the scope of the present paper. However, MH's growing relevance in the management of IBD has definitely influenced the challenges of endoscopic evaluation of disease activity.

Although different diseases have different issues, on a fundamental level an endoscopic score is needed to codify the different grades of intestinal disease activity observed during an endoscopic examination in a quantitative, simple, reproducible, and acceptable way. An early issue in the development of a scoring system has been the identification of high-risk lesions that are easily recognizable during an endoscopy. In addition, the increased complexity of the evaluation has led to growing disagreement between different operators (inter-observer variability) and even in repeated evaluations by the same operator (intra-observer variability). It is crucial to develop a score that will reduce such variation and standardize the interpretation of results in both trials and clinical practice 
[5]. The gradual shift from a symptom-based to a mucosal-based approach for IBD has led to new interest in the issue of endoscopic scores and reconsideration of the finality of the score itself. There has been a transition from the target to the gradation of endoscopic severity and therefore to the discrimination of patients based on disease severity and identification of the subset of patients meeting the MH criteria, despite MH's variable definition. Such attempts cannot be finalized because no clear definition has been stated for $\mathrm{MH}$ in either UC or $\mathrm{CD}$. For the latter disease, clinical trials generally refer to the absence of ulcer, while for UC, most trials refer to a Mayo endoscopic score of 0-1 [6]. The lack of a validated cut-off for endoscopic scores in CD and the limitation of the current Mayo definition of $0-1$ in UC further confirm that $\mathrm{MH}$ is yet to be clearly defined. In UC in particular, the current belief that endoscopic score of 0 and 1 have the same prognostic relevance has recently been challenged $[7,8]$, and the finding of a relatively higher number of patients with endoscopic healing, as previously defined, than with clinical remission in some trials, such as ULTRA and PURSUIT [9,10], has raised additional questions about the definition of $\mathrm{MH}$. Currently, primary end-points in clinical trials are still represented by clinical parameters and composite indexes, including symptoms, signs and lab tests. The scarce applicability of such parameters in clinical practice is decisively pushing toward the identification and better clarification of appropriate new end-points, and among these, endoscopic disease activity evaluation is one objective parameter that should be included [11].

The relevance of a correct evaluation of disease activity and of agreement among operators has been strongly reinforced by a recent observation that different evaluations of endoscopic reports, such as the evaluation by a 'central reader', may profoundly alter the report of a trial. In a randomized, double-blind, placebo-controlled, multicenter study investigating the safety and efficacy of a delayedreleased mesalamine formulation in UC patients, the primary end-point of clinical remission at week 6 was not achieved in the original intention-to-treat analysis (30 vs. $20.6 \%$ in the treated vs. placebo group, $p=0.069$ ). Instead, it was observed after a central reading revision by seven expert readers who independently analyzed sigmoidoscopy recordings ( 29 vs. $13.8 \%$ in the treated vs. placebo group, $p=0.011$ ) and excluded 87 of 281 patients (31\%) from the original population because they did not meet the inclusion criteria [12].

\section{Ulcerative colitis}

The evolution of the concept of endoscopic score is particularly evident in UC because the role of the endoscopic activity in disease management has long been recognized. Numerous scores have been used for the assessment of endoscopic activity in UC, and a recent systematic review identified 31 scoring systems proposed in the literature [13]. Among these, very few were constantly utilized in clinical trials. Early in 1937, Bargen et al. described the importance of directly evaluating the mucosa of patients with ulcerative colitis using a rigid proctoscope in conjunction with a magnifying attachment [14], but the first endoscopic score to evaluate disease activity in UC patients in a clinical trial was proposed by Truelove and Witts in 1955 [15]. In 1964, Baron et al. developed a score to evaluate the appearance of rectosigmoid mucosa using a rigid proctoscope, in which disease activity was expressed by severity of bleeding and friability without considering ulcerations [16]. The Baron score was modified by Feagan et al., in 2005, with the removal of the qualitative assessment of different levels of bleeding, and the inclusion of ulceration in the evaluation [17]. Baron score has represented for a long time the most frequently used endoscopic score in clinical trials. Its modified version represents a simple and efficacious tool to evaluate endoscopic activity, but the lack of an appropriate validation and the unclear definition of MH may limit the utilization of the score in the future.

In 1987, Schroeder et al. described an instrument to measure disease activity called the Mayo score, which included both endoscopic and clinical items [18]. The part of this composite score that evaluate endoscopic activity, namely the Mayo endoscopic subscore (MES), is the scoring system most widely used in clinical trials to describe endoscopic activity as easily reproducible. It is characterized by 4 components and scores range from 0 to 3 , with 0 indicating inactive disease with normal mucosa; 1 indicating mild disease (erythema and mild friability); 2 indicating moderate disease (marked erythema, friability, absent vascular pattern and erosions); and 3 indicating severe disease (spontaneous bleeding and diffuse ulceration). MH was defined as a MES of 0 or 1 , which predicts a better outcome than a MES of 2 or 3 with an associated reduction in colectomy. MES has been used in multiple clinical trials [13]. Its main limitations are the fact that the definition of $\mathrm{MH}$, although commonly used, has not been validated, and as mentioned above, recent data suggest a difference prognostic relevance between the scores of 0 and 1 [7]. Moreover, the score does not discriminate between superficial and deep ulcerations, and grades 1 and 2 may present significant overlap. Osada et al. found adequate inter- and intra-observer agreement from the experts, but agreement was markedly lower when trainees were involved in the scoring [19]. More recently, the suboptimal agreement of the score was confirmed, and surprisingly, the agreement coefficient was higher among non-expert than expert gastroenterologists (kappa $=0.71$ vs. 0.53 , respectively) [20].

The need for a better definition of endoscopic activity and the lack of a fully validated tool have recently led to the proposal of new indexes in an attempt to increased inter-observer agreement. In 2012, Travis et al. proposed the Ulcerative Colitis Endoscopic Index of Severity (UCEIS) [21], and, in a subsequent study, the authors evaluated the reliability of the UCEIS and validated it with an independent cohort of investigators [22]. The UCEIS score represents a validated index of endoscopic severity of UC, and it is considered a useful tool in clinical practice for reducing variations between different observers. However, it has several limitations. As for other indexes, the definition of $\mathrm{MH}$ remains unclear. In addition, the thresholds for mild to moderate and severe disease have not been completely validated. Only the most severely affected part of the mucosa is scored, meaning that disease extension is not evaluated. Most importantly, even though the score offers a detailed description of mucosal inflammation, a real advantage in the interobserver agreement over simpler scores, such as Baron and MES, has yet to be demonstrated [12].

In an attempt to include disease extension and to increase inter-observer agreement, the Ulcerative Colitis Colonoscopic Index of Severity (UCCIS) was recently proposed [23]. The score shows significant correlation with the clinical indexes, laboratory measurement of active disease, and good correlation with patientdefined remission. Therefore, the UCCIS may represent a useful tool based on the evaluation of each colonic segment that provides reproducible results in endoscopic scoring of patients with UC. However, such a score presents some limitations. First, the original study for the development of the score was a single-center study of only 50 patients, and larger studies are needed to validate the usefulness of this index. Second, calculating the score requires a total colonoscopy, which is a more expensive and invasive procedure that is less well tolerated by the patient compared to sigmoidoscopy. Moreover, UCCIS is pretty more complex comparing with other scores and therefore its widespread utilization in every endoscopic center may not be feasible.

Very recently, to conjugate the simplicity of the MES with the need to evaluate disease extension, a Modified Mayo Endoscopic Score (MMES) was proposed [24]. Lobaton et al. calculated this new 
Table 1

Most frequently used and more recently proposed endoscopic scores in UC.

\begin{tabular}{|c|c|c|c|}
\hline Score [year] & Calculation & Pro & Contra \\
\hline $\begin{array}{l}\text { Modified Baron Index } \\
\text { [2005] }\end{array}$ & $\begin{array}{l}\text { Stepwise } 5 \text { grade scale: } \\
\text { Normal mucosa }(0) \\
\text { granular with an abnormal vascular } \\
\text { pattern ( } 1 \text { ) } \\
\text { friable ( } 2) \\
\text { microulcerations with spontaneous } \\
\text { bleeding ( } 3 \text { ) } \\
\text { gross ulceration (4) }\end{array}$ & $\begin{array}{l}\text { Easy in clinical practice } \\
\text { Require only rectosigmoidoscopy }\end{array}$ & $\begin{array}{l}\text { Not validated } \\
\text { No definition of } \mathrm{MH} \\
\text { Not considering disease extension } \\
\text { Low agreement for granularity and } \\
\text { erythema }\end{array}$ \\
\hline $\begin{array}{l}\text { Mayo endoscopic subscore } \\
\text { (MES) [1987] }\end{array}$ & $\begin{array}{l}\text { Stepwise } 4 \text { grade scale: } \\
\text { Normal }(0) \text { : no inflammatory signs } \\
\text { Mild ( } 1) \text { : erythema } \\
\text { Moderate (2): friability, erosions } \\
\text { Severe (3): spontaneous bleeding, } \\
\text { ulcerations }\end{array}$ & $\begin{array}{l}\text { Easy in clinical practice } \\
\text { Prospective study } \\
\text { Most used in clinical practice and } \\
\text { clinical trials } \\
\text { Require only rectosigmoidoscopy }\end{array}$ & $\begin{array}{l}\text { Overlap grade } 1-2 \\
\text { Low interobserver agreement } \\
\text { Not considering disease extension } \\
\text { Definition of } \mathrm{MH} \text { questionable }\end{array}$ \\
\hline $\begin{array}{l}\text { Ulcerative Colitis } \\
\text { Endoscopic Index of } \\
\text { severity (UCEIS) [2012] }\end{array}$ & $\begin{array}{l}\text { Total score (3-11) from the sum of } 3 \\
\text { components: } \\
\text { Vascular pattern: normal ( } 1 \text { ), patchy } \\
\text { obliteration (2), obliterated (3) } \\
\text { Bleeding: none (1), mucosal (2), } \\
\text { luminal mild ( } 3 \text { ), luminal } \\
\text { moderate-severe (4) } \\
\text { Lesions: none (1), erosions (2), } \\
\text { superficial ulcer ( } 3 \text { ), deep ulcer (4) }\end{array}$ & $\begin{array}{l}\text { Validated } \\
\text { High interobserver reproducibility } \\
\text { Require only rectosigmoidoscopy }\end{array}$ & $\begin{array}{l}\text { No definition of } \mathrm{MH} \\
\text { Not considering disease extension } \\
\text { No established thresholds for mild, } \\
\text { moderate } \\
\text { and severe disease } \\
\text { Definition of superficial vs. deep ulcer }\end{array}$ \\
\hline $\begin{array}{l}\text { Ulcerative Colitis } \\
\text { Colonoscopic Index of } \\
\text { severity (UCCIS) [2013] }\end{array}$ & $\begin{array}{l}\text { Total score }(0-162)=3.1 \times(\text { sum of } A \text { in } \\
5 \text { tracts })+3.6 \times(\text { sum of B })+3.5 \times(\text { sum } \\
\text { of } C)+2.5 \times(\text { sum of D }) \\
\text { (A) Vascular pattern: normal }(0) \text {, } \\
\text { partially visible }(1) \text {, complete loss }(2) \\
\text { (B) Granularity: normal }(0) \text {, fine }(1) \text {, } \\
\text { coarse ( } 2) \\
\text { (C) Lesions: none }(0) \text {, erosions or } \\
\text { pinpoint ulcers }(1) \text {, numerous shallow } \\
\text { ulcers }(2) \text {, deep ulcer }(3) \text {, diffuse } \\
\text { ulceration ( } 4) \\
\text { (D) Friability/bleeding: none }(0) \text {, } \\
\text { friability ( } 1) \text {, spontaneous bleeding ( } 2)\end{array}$ & $\begin{array}{l}\text { Consider disease extension } \\
\text { Significant correlation with clinical } \\
\text { index and laboratory tests } \\
\text { Significant interobserver agreement }\end{array}$ & $\begin{array}{l}\text { Not validated in a different casistic } \\
\text { Single center study (only } 50 \text { patients) } \\
\text { Requires total colonoscopy } \\
\text { No definition of MH } \\
\text { No established thresholds for mild, } \\
\text { moderate and severe disease }\end{array}$ \\
\hline $\begin{array}{l}\text { Modified Mayo Endoscopic } \\
\text { Score (MMES) [2015] }\end{array}$ & $\begin{array}{l}\text { Total score }=(\text { sum of MES in } 5 \\
\text { tracts }) \times \text { disease extent }(\mathrm{dm}) / \text { no. of } \\
\text { segment with active inflammation } \\
(\mathrm{MES} \geq 1)\end{array}$ & $\begin{array}{l}\text { Consider disease extension } \\
\text { Easy in clinical practice } \\
\text { Significant correlation with clinical } \\
\text { index, laboratory tests and histology } \\
\text { Complete colonoscopy not essential }\end{array}$ & $\begin{array}{l}\text { Not validated in a different casistic } \\
\text { Inter-observer agreement not assessed } \\
\text { No established thresholds for mild, } \\
\text { moderate and severe disease }\end{array}$ \\
\hline
\end{tabular}

Abbreviations: $\mathrm{MH}=$ mucosal healing; $\mathrm{MES}=$ Mayo endoscopic subscore .

score by multiplying the sum of the MES values of the 5 colonic segments (rectum, sigmoid, descending, transverse, and ascending colon) by the total extension of inflammation (in decimeters - $\mathrm{dm}$ ) and dividing that by the number of segments with active inflammation ( $M E S \geq 1)$. The MMES showed significant correlation with fecal calprotectin $(r=0.73)$, clinical index $(r=0.54)$, and histologic score $(r=0.62)$. Because of its simplicity and correlation with different parameters of disease activity, the MMES is a promising and feasible tool not only in trials but even in clinical practice. However, considering that MMES has been just very recently developed, further studies are needed to better assess the validity of the score (i.e., inter-observer agreement was not assessed yet) and its potential application in UC patients.

The most frequently used and more recently developed scores in UC are summarized in Table 1.

The importance of the ongoing problem of endoscopic evaluation of UC is highlighted by the fact that, despite the first scores dating back to the 1950s, new scores have been proposed in the last 2-3 years. On the one hand, this has led to the attempt of a more homogenous definition for patients with inactive disease (mucosal healing) by synthesizing the best features of the most frequently used scores (Mayo and Baron) in the development of the UCEIS score. On the other hand, there is a renewed focus on the challenge of evaluating disease extension. Most of the currently used scores in UC calculate only the activity of the most inflamed colonic segment (generally rectum/sigma) to enable the calculation of the score from recto-sigmoidoscopy. This could have a concrete advantage of avoiding a complete colonoscopy, which is a more expensive and time-consuming procedure that could be inappropriate in specific situations (i.e., severe flares). However, the extent of mucosal inflammation is clearly one of the most important factors to determine disease course [1], and not including disease extension in the endoscopic score may be a limitation. If the score considers only a segment of colon, patients with completely different clinical situations, such as severe proctitis and severe pancolitis, may have the same endoscopic score. Moreover, a score determined by evaluating only the most affected tract may not reflect the possible progression of the disease in proximal areas (possible in up to $50 \%$ of patients [25]) because the numeric score would not change. Finally, the possibility of patchy healing of the colon in treated UC has been highlighted [26,27]. The limitations of an assessment of disease activity based only on a sigmoidoscopy have recently been highlighted by a retrospective analysis of 545 colonoscopic evaluations of UC patients in which the most inflamed segment was found proximal to the splenic flexure in $27 \%$ of cases. Severe activity (Mayo endoscopic 
Table 2

Most frequently used endoscopic scores in CD.

\begin{tabular}{|c|c|c|c|}
\hline Score [year] & Calculation & Pro & Contra \\
\hline CDEIS [1989] & $\begin{array}{l}\text { Total score }(0-44)=\text { sum of } 5 \text { segments } \\
\text { score } / \text { no. of explored } \\
\text { segments + ulcerated stenosis (yes }=3 \text {, } \\
\text { no }=0)+ \text { non-ulcerated stenosis } \\
(\text { yes }=3, \text { no }=0 \text { ) } \\
\text { *segment score from the sum of: } \\
\text { deep ulceration (yes }=12, \text { no }=0 \text { ) } \\
\text { superficial ulceration }(\text { yes }=6, \text { no }=0 \text { ) } \\
\text { surface involved }(0-10) \\
\text { surface ulcerated }(0-10)\end{array}$ & $\begin{array}{l}\text { Gold standard } \\
\text { Validated } \\
\text { Prospective study } \\
\text { Extensively applied in clinical trials }\end{array}$ & $\begin{array}{l}\text { Complexity } \\
\text { No definition of } \mathrm{MH} \\
\text { No correlation with CDAI }\end{array}$ \\
\hline SES-CD [2004] & $\begin{array}{l}\text { Total score }(0-56)=\text { sum of } 5 \text { segments } \\
\text { score including the sum of: } \\
\text { Ulcer: none }(0), 0.1-0.5 \mathrm{~cm}(1) \text {, } \\
0.5-2 \mathrm{~cm}(2),>2 \mathrm{~cm}(3) \\
\text { Ulcerated surface: none }(0),<10 \%(1) \text {, } \\
\text { 10-30\%(2), >30\%(3) } \\
\text { Affected surface: none }(0),<50 \%(1) \text {, } \\
50-75 \%(2),>75 \%(3) \\
\text { Narrowing: none }(0) \text {, single passable(1), } \\
\text { multiple passable(2), unpassable(3) }\end{array}$ & $\begin{array}{l}\text { Validated } \\
\text { Prospective study } \\
\text { Simpler than CDEIS } \\
\text { Correlated with CDEIS }\end{array}$ & $\begin{array}{l}\text { No definition of } \mathrm{MH} \\
\text { No correlation with CDAI } \\
\text { Less applied in clinical trials }\end{array}$ \\
\hline Rutgeerts [1990] & $\begin{array}{l}\text { Stepwise } 5 \text { grade scale: } \\
\text { I0 - no lesions in neo-terminal ileum } \\
\text { I1 - <5 aphthous lesions in } \\
\text { neo-terminal ileum } \\
\text { I } 2->5 \text { aphthous lesions with normal } \\
\text { mucosa, skip areas with larger lesions, } \\
\text { anastomotic lesions } \\
\text { I3 - diffuse aphthous ileitis } \\
\text { I } 4 \text { - diffuse inflammation with ulcer, } \\
\text { nodules and/or stenosis }\end{array}$ & $\begin{array}{l}\text { Prospective study } \\
\text { Extensively applied in clinical trials } \\
\text { Strong prognostic relevance }\end{array}$ & $\begin{array}{l}\text { No formal validation } \\
\text { Only in post-operative ileo-colonic } \\
\text { resection }\end{array}$ \\
\hline
\end{tabular}

Abbreviations: $\mathrm{MH}=$ mucosal healing; $\mathrm{CDAI}=$ Crohn's disease activity index.

score $=3$ ) was more frequently found in proximal than in distal segments, and $40 \%$ of patients with inflamed mucosa in the proximal tracts had no inflammation in the rectum-sigmoid colon [28]. Our group has recently reported that the UCEIS calculated as a sum of 5 colonic segments (total UCEIS - tU) performed better than the regular UCEIS in term of correlation with clinical index and prognostic value [29]. Considering the relevance of the issue, the most recently proposed indexes, namely the UCCIS and the MMES, include the assessment of disease extension in their calculation, but the debate is still open [30]. It is noteworthy that, despite the proposal of different scores, the reproducibility optimization still remains an unmet goal in the evaluation of endoscopic activity in UC patients, probably due to the intrinsic nature of the disease.

\section{Crohn's Disease}

As previously mentioned, the endoscopic evaluation of $C D$ has many challenges. It is well known that symptoms may not correlate with the activity of disease as measured by endoscopic and cross-sectional imaging techniques [31], and the clinical Crohn's Disease Activity Index (CDAI) still represent the reference parameter in clinical trials for disease activity assessment. However, the need to overcome a simply symptom-based approach and the relevance of intestinal healing as a therapeutic end-point affect the management of $C D$ patients as well, and validated endoscopic scores have been developed for this purpose. A recent systematic review identified 9 endoscopic scores for CD [32]. Among these, two had undergone an appropriate validation process [33,34], and the Rutgeerts score [35], represents a widely used tool in the postoperative setting, despite its lack of formal validation.

The first validated endoscopic evaluative score for CD severity is the Crohn's Disease Endoscopic Index of Severity (CDEIS), presented by the Groupe D'Etudes Therapeutiques Des Affections Inflammatoires due Tube Digestif (GETAID) in 1989 in a multiphase and prospective study [33]. In the first development phase, two endoscopists simultaneously evaluated colonoscopies from 75 patients, with one endoscopist observing the other during the procedure. The calculation of the total score (range 0-44) was derived from a formula that included the presence of deep or superficial ulceration, the extent of ulcerated and inflamed mucosa, and the presence of ulcerated and non-ulcerated stenosis, in 5 ileocolonic segments (rectum, sigmoid/left, transverse, right colon and ileum). A limitation of this approach could be fact that the two endoscopists scored the items while physically present in the same procedure room, therefore limiting the independence of the observations. Furthermore, segments that were not evaluated because of technical difficulties, anastomotic narrowing, or surgery were not considered for these calculations even though they could represent important aspects. In terms of the validation phase, a recent study reported that a central reading of the CDEIS to assess CD severity by a group of 4 readers had excellent intra- and inter-observer reliability (intra-observer ICC, 0.89; 95\% confidence interval [CI], 0.86-0.93 and inter-observer ICC, 0.71; 95\% CI, 0.61-0.79) [32]. Potential limitations include no stated definition of $\mathrm{MH}$ and the fact that the CDEIS does not correlate with CDAI [36]. Moreover, the complexity of the calculation is the real limitation to the widespread use of the score. However, the CDEIS still represent the gold standard for endoscopic activity evaluation in CD. In fact, the CDEIS has been used as an inclusion criterion in some studies and as end-point in several clinical trials [32].

In 2004, to simplify the complexity of CDEIS, Daperno et al. used a prospective study to develop the Simple Endoscopic Score in Crohn's Disease (SES-CD) [34]. The four parameters of the CDEIS with high inter-observer agreement were adopted in the SES-CD: ulcer size, proportion of surface covered by the ulcer, proportion of surface covered by other lesions and luminal stenosis. Each descriptor was graded in a stepwise manner, and the total score was calculated as the sum of all the items in each segment, with a range 
of 0 to 56. Agreement for the items was again assessed by two endoscopists who graded 71 colonoscopies, resulting in inter-observer ICCs for the SES-CD and CDEIS of 0.98 and 0.90 , respectively. As in the CDEIS validation, the agreement phase was determined by two endoscopists who evaluated the same procedure simultaneously. Although the endoscopists scored the colonoscopy without communicating, they may have been influenced by one another. In terms of the validation phase, Khanna et al. reported that a central reading of the SES-CD by a group of 4 readers to assess CD severity had very good intra- and inter-observer reliability (intraobserver ICC, 0.89; 95\% CI, 0.86-0.93 and inter-observer ICC, 0.71; $95 \%$ CI, 0.63-0.76) [37]. The SES-CD simplified index was highly correlated with the CDEIS (Spearman's $r=0.883$ ), and this correlation became almost perfect when both scales were scored by a single endoscopist (Spearman's $r=0.938, p<0.0001$ ) [38]. The relationship between score and disease activity has not been clearly defined; however, two studies $[39,40]$ have proposed a correlation between scoring and inflammation [remission (0-2), mild inflammation (3-6), moderate inflammation (7-16) and severe inflammation ( $>16)$ ]. Because of the high degree of correlation between the CDEIS and the simplicity of its application, the SES-CD has been used in clinical trials [32] and may even be implemented in clinical practice. In the CDEIS, no clear definition for MH has been provided.

One of the most frequently used endoscopic scores is the Rutgeerts score for postoperative CD recurrence. It was formally developed 1990 by examining 89 patients with ileal resection for $\mathrm{CD}$ and observing clinical outcomes in patients with early neoterminal ileum lesions. A 5-grade stepwise numeric index was developed for the gradation of endoscopic postoperative recurrence in the neo-terminal ileum. Patients with lower scores had a better prognosis than those with more severe endoscopic lesions [35]. Although the score have been used in both trials and clinical practice, only a few very recent studies have explored intra- and inter-observer agreement, which opens the door to a formal validation $[41,42]$. For its consistent correlation with prognosis, the Rutgeerts score is the best example of the application of a clinical score to the concrete management of patients, and in the specific subset of post-operative patients, it is probably the most obvious confirmation of the role of $\mathrm{MH}$ in disease outcome. For that reason, the score has recently been included in a clinical trial that represent the first treat-to-target study in which endoscopic activity has been considered a primary end-point for decision-making (POCER) [43]. Moreover, it has been used extensively to determine efficacy in clinical trials in post-operative CD patients [32].

Table 2 summarizes the most commonly used endoscopic scores in $\mathrm{CD}$.

\section{Conclusion}

The challenge of endoscopic evaluation of disease activity in IBD is far from solved. In UC, several different scores have been proposed, but not one has been definitely adopted as the 'gold standard' for endoscopic activity evaluation. In CD, the importance of the endoscopic evaluation has only recently been highlighted. The application of endoscopic scores has been strongly influenced in the last decade by the increasing relevance of the $\mathrm{MH}$ as an important end-point for the management of IBD. In addition to the current limitations and the over-estimation of the MH concept, the key relevance of the endoscopic evaluation for IBD assessment and management has been underlined in recent years. Consequently, both old and new challenges relative to the application of endoscopic scores are being considered and evaluated extensively. Available data indicating that the current methods available to evaluate endoscopic disease activity are sub-optimal are increasing rapidly, and the same $\mathrm{MH}$ does not yet have a universally accepted definition. Because the widespread use of central readers to improve the quality and agreement of endoscopic reports is not feasible, a concrete solution appears to be the implementation of efficient scores that may reduce variability and improve the quality of endoscopic reports. To accomplish this, a more intense commitment by scientific societies to implement correct utilization of endoscopic scores is desirable. The education and training of endoscopists could lead to consistent improvements in the interobserver agreement and reproducibility of the endoscopic reports, as recently shown in the preliminary results of an Italian endoscopic educational program [44]. In the longer term, the progress of available tools (i.e., high-definition endoscopes), may contribute to a more accurate definition of endoscopic activity, as indicated by a preliminary study [45]. Moreover, the wider availability of multimedia tools in the endoscopic room will probably lead to the utilization and transfer of video for a more complete evaluation of endoscopic activity in IBD patients.

\section{Conflict of interest}

None declared.

\section{References}

[1] Ordas I, Eckmann L, Talamini M, et al. Ulcerative colitis. The Lancet 2012;380:1606-19.

[2] Baumgart DC, Sandborn WJ. Crohn's disease. The Lancet 2012;380:1590-605.

[3] Neurath MF, Travis SP. Mucosal healing in inflammatory bowel diseases: a systematic review. Gut 2012:61:1619-35.

[4] Pagnini C, Menasci F, Festa S, et al. Mucosal healing in ulcerative colitis: between clinical evidence and market suggestion. World Journal of Gastrointestinal Pathophysiology 2014;5:54-62.

[5] Daperno M, Castiglione F, de Ridder L, et al. Results of the 2nd part Scientific Workshop of the ECCO. II: Measures and markers of prediction to achieve, detect, and monitor intestinal healing in inflammatory bowel disease. Journal of Crohn's \& Colitis 2011;5:484-98.

[6] Mazzuoli S, Guglielmi FW, Antonelli E, et al. Definition and evaluation of mucosal healing in clinical practice. Digestive and Liver Disease: Official Journal of the Italian Society of Gastroenterology and the Italian Association for the Study of the Liver 2013:45:969-77.

[7] Manginot C, Baumann C, Peyrin-Biroulet L. An endoscopic Mayo score of 0 is associated with a lower risk of colectomy than a score of 1 in ulcerative colitis. Gut 2015;64:1181-2.

[8] Ardizzone S, Cassinotti A, Duca P, et al. Mucosal healing predicts late outcomes after the first course of corticosteroids for newly diagnosed ulcerative colitis. Clinical Gastroenterology and Hepatology: The Official Clinical Practice Journal of the American Gastroenterological Association 2011:9:483-9, e3.

[9] Sandborn WJ, van Assche G, Reinisch W, et al. Adalimumab induces and maintains clinical remission in patients with moderate-to-severe ulcerative colitis. Gastroenterology 2012;142:257-65, e1-3.

[10] Sandborn WJ, Feagan BG, Marano C, et al. Subcutaneous golimumab induces clinical response and remission in patients with moderate-to-severe ulcerative colitis. Gastroenterology 2014;146:85-95, quiz e14-5.

[11] Levesque BG, Sandborn WJ, Ruel J, et al. Converging goals of treatment of inflammatory bowel disease from clinical trials and practice. Gastroenterology 2015;148:37-51, e1.

[12] Feagan BG, Sandborn WJ, D'Haens G, et al. The role of centralized reading of endoscopy in a randomized controlled trial of mesalamine for ulcerative colitis. Gastroenterology 2013;145:149-57, e2.

[13] Samaan MA, Mosli MH, Sandborn WJ, et al. A systematic review of the measurement of endoscopic healing in ulcerative colitis clinical trials: recommendations and implications for future research. Inflammatory Bowel Diseases 2014;20:1465-71.

[14] Bargen JA. The Medical Management of Chronic Ulcerative Colitis: (Section of Surgery: Sub-Section of Proctology). Proceedings of the Royal Society of Medicine 1937;30:351-62.

[15] Truelove SC, Witts LJ. Cortisone in ulcerative colitis; final report on a therapeutic trial. British Medical Journal 1955;2:1041-8.

[16] Baron JH, Connell AM, Lennard-Jones JE. Variation between observers in describing mucosal appearances in proctocolitis. British Medical Journal 1964:1:89-92

[17] Feagan BG, Greenberg GR, Wild G, et al. Treatment of ulcerative colitis with a humanized antibody to the alpha4beta7 integrin. New England Journal of Medicine 2005;352:2499-507.

[18] Schroeder KW, Tremaine WJ, Ilstrup DM. Coated oral 5-aminosalicylic acid therapy for mildly to moderately active ulcerative colitis. A randomized study. New England Journal of Medicine 1987;317:1625-9. 
[19] Osada T, Ohkusa T, Yokoyama T, et al. Comparison of several activity indices for the evaluation of endoscopic activity in UC: inter- and intraobserver consistency. Inflammatory Bowel Diseases 2010;16:192-7.

[20] Daperno M, Comberlato M, Bossa F, et al. Inter-observer agreement in endoscopic scoring systems: preliminary report of an ongoing study from the Italian Group for Inflammatory Bowel Disease (IG-IBD). Digestive and Liver Disease: Official Journal of the Italian Society of Gastroenterology and the Italian Association for the Study of the Liver 2014;46:969-73.

[21] Travis SP, Schnell D, Krzeski P, et al. Developing an instrument to assess the endoscopic severity of ulcerative colitis: the Ulcerative Colitis Endoscopic Index of Severity (UCEIS). Gut 2012;61:535-42.

[22] Travis SP, Schnell D, Krzeski P, et al. Reliability and initial validation of the ulcerative colitis endoscopic index of severity. Gastroenterology 2013;145:987-95.

[23] Samuel S, Bruining DH, Loftus Jr EV et al. Validation of the ulcerative colitis colonoscopic index of severity and its correlation with disease activity measures. Clinical Gastroenterology and Hepatology: The Official Clinical Practice Journal of the American Gastroenterological Association 2013;11:49-54, e1.

[24] Lobaton T, Bessissow T, De Hertogh G, et al. The Modified Mayo Endoscopic Score (MMES): a new index for the assessment of extension and severity of endoscopic activity in ulcerative colitis patients. Journal of Crohn's \& Colitis 2015;9:846-52.

[25] Langholz E, Munkholm P, Davidsen M, et al. Changes in extent of ulcerative colitis: a study on the course and prognostic factors. Scandinavian Journal of Gastroenterology 1996;31:260-6.

[26] Bernstein CN, Shanahan F, Anton PA, et al. Patchiness of mucosal inflammation in treated ulcerative colitis: a prospective study. Gastrointestinal Endoscopy $1995 ; 42: 232-7$

[27] Kim B, Barnett JL, Kleer CG, et al. Endoscopic and histological patchiness in treated ulcerative colitis. American Journal of Gastroenterology 1999;94:3258-62.

[28] Kato J, Kuriyama M, Hiraoka S, et al. Is sigmoidoscopy sufficient for evaluating inflammatory status of ulcerative colitis patients. Journal of Gastroenterology and Hepatology 2011;26:683-7.

[29] Menasci F, Pagnini C, Di Giulio E. Disease Extension Matters in Endoscopic Scores: UCEIS calculated as a sum of the single colonic segments performed better than regular UCEIS in outpatients with ulcerative colitis. Journal of Crohn's \& Colitis 2015;9:692-3.

[30] Travis S, Corte C, Keshav S. Does disease extent matter when scoring the UCEIS? Journal of Crohn's \& Colitis 2015;9:694.

[31] Benitez JM, Meuwis MA, Reenaers C, et al. Role of endoscopy, cross-sectional imaging and biomarkers in Crohn's disease monitoring. Gut 2013;62:1806-16.

[32] Khanna R, Bouguen G, Feagan BG, et al. A systematic review of measurement of endoscopic disease activity and mucosal healing in Crohn's disease: recommendations for clinical trial design. Inflammatory Bowel Diseases 2014;20:1850-61

[33] Mary JY, Modigliani R. Development and validation of an endoscopic index of the severity for Crohn's disease: a prospective multicentre study. Groupe d'Etudes Therapeutiques des Affections Inflammatoires du Tube Digestif (GETAID). Gut 1989;30:983-9.

[34] Daperno M, D'Haens G, Van Assche G, et al. Development and validation of a new, simplified endoscopic activity score for Crohn's disease: the SES-CD. Gastrointestinal Endoscopy 2004;60:505-12.

[35] Rutgeerts P, Geboes K, Vantrappen G, et al. Predictability of the postoperative course of Crohn's disease. Gastroenterology 1990;99:956-63.

[36] Cellier C, Sahmoud T, Froguel E, et al. Correlations between clinical activity endoscopic severity, and biological parameters in colonic or ileocolonic Crohn's disease. A prospective multicentre study of 121 cases. The Groupe d'Etudes Therapeutiques des Affections Inflammatoires Digestives. Gut 1994;35:231-5.

[37] Khanna R, Zou G, D'Haens G, et al. Reliability among central readers in the evaluation of endoscopic findings from patients with Crohn's disease. Gut 2015, gutjnl-2014-308973.

[38] Sipponen T, Nuutinen H, Turunen U, et al. Endoscopic evaluation of Crohn's disease activity: comparison of the CDEIS and the SES-CD. Inflammatory Bowel Diseases 2010;16:2131-6.

[39] af Bjorkesten CG, Nieminen U, Turunen U, et al. Surrogate markers and clinical indices, alone or combined, as indicators for endoscopic remission in antiTNF-treated luminal Crohn's disease. Scandinavian Journal of Gastroenterology 2012:47:528-37.

[40] Schoepfer AM, Beglinger C, Straumann A, et al. Fecal calprotectin correlates more closely with the Simple Endoscopic Score for Crohn's disease (SES-CD) than CRP, blood leukocytes, and the CDAI. American Journal of Gastroenterology 2010;105:162-9.

[41] Gecse K, Löwenberg M, Bossuyt P, et al. P285 agreement among experts in the endoscopic evaluation of postoperative recurrence in Crohn's disease using the Rutgeerts score. Journal of Crohn's and Colitis 2014:S182.

[42] Kennedy NA, Ennis H, Gaya DR, et al. P308 interobserver agreement in assessment of Rutgeerts' score of endoscopic recurrence of ileal Crohn's disease: a substudy of the TOPPIC trial. In: ECCO Congress. 2015.

[43] De Cruz P, Kamm MA, Hamilton AL, et al. Crohn's disease management after intestinal resection: a randomised trial. The Lancet 2015;385:1406-17.

[44] Daperno M, Comberlato M, Bossa F, et al. P452 increasing interobserver agreement on IBD endoscopic scoring systems: results from the IGIBDEndo educational program. Journal of Crohn's \& Colitis 2014;8:S254-5.

[45] Iacucci M, Gasia MF, Hassan C, et al. Complete mucosal healing defined by endoscopic Mayo subscore still demonstrates abnormalities by novel high definition colonoscopy and refined histological gradings. Endoscopy 2015;47:726-34. 